\title{
The Significance of Hypoalbumineamia and Hypoproteinemia in Patients with Stroke
}

\author{
Hassan Naji Aboud1, Haider Ali Mohammed1, Mohammed Majeed Kamil2, Bahaa Hassan³ \\ ${ }^{1}$ Neurology Department at Neurosurgery Teaching Hospital, Baghdad, Iraq \\ ${ }^{2}$ Neurology Department at Baquba Teaching Hospital, Baquba, Iraq \\ ${ }^{3}$ Neurology Department at Neurosciences Teaching Hospital, Baghdad, Iraq \\ Email: dr-haidarali@yahoo.com
}

How to cite this paper: Aboud, H.N., Mohammed, H.A., Kamil, M.M. and Hassan, B. (2018) The Significance of Hypoalbumineamia and Hypoproteinemia in Patients with Stroke. Neuroscience \& Medicine, 9, 105-115.

https://doi.org/10.4236/nm.2018.93011

Received: February 25, 2018

Accepted: August 7, 2018

Published: August 10, 2018

Copyright (c) 2018 by authors and Scientific Research Publishing Inc. This work is licensed under the Creative Commons Attribution International License (CC BY 4.0).

http://creativecommons.org/licenses/by/4.0/

Open Access

\begin{abstract}
Objective: To determine if there is any significant association between stroke and both hypoalbuminema and hypoproteinemia. Patients and Methods: Total serum proteins "T.S.P." and serum albumin were measured for $65 \mathrm{pa}$ tients with stroke who were admitted to the medical and neurological wards at Baghdad Teaching Hospital in the Medical City from November 2003 to October 2004. Careful history was obtained and proper clinical examinations were done. Serum albumin, T.S.P., blood sugar, renal function, liver function and general urine examination "G.U.E." were tested within 48 - 72 hours of the start of patient symptoms. These patients with hepatic and renal dysfunction and those with diabetes mellitus were excluded. The results were compared with the results obtained from control group, which consisted of 40 persons of matched age and sex. By application pf chi square test " $X$ " to see the association of serum albumin with cigarette smoking, age, hypertension and the presence of carotid bruit. Results: The mean serum level of T.S.P. and serum albumin of those with stroke was $6.42 \pm 0.322 \mathrm{~g} / \mathrm{dl}, 3.26 \pm 0.251 \mathrm{~g} / \mathrm{dl}$ respectively, which was significantly lower than T.S.P. and serum albumin of the control "mean $=7.8 \pm 0.257 \mathrm{~g} / \mathrm{dl}, 4.73 \pm 0.206 \mathrm{~g} / \mathrm{dl}$ respectively" $[\mathrm{P}<0.001]$. This study reveals that there is an inverse relationship between the age $\left[X^{2}=\right.$ 25.14, $\mathrm{P}<0.005]$, number of cigarettes $\left[X^{2}=15.57, \mathrm{P}<0.025\right]$ and the blood pressure with serum albumin $\mathrm{P}<0.0005$, and the presence of carotid bruit is associated with low level of albumin $\mathrm{P}<0.005$ "Fisher's test". Conclusion: Hypoalbuminemia and hypoproteinemia are significantly associated with stroke.
\end{abstract}

\section{Keywords}

Hypoalbuminemia, Hypoproteinemia, Stroke, Myocardial Infarction 


\section{Introduction}

Atherosclerosis is an arterial disease that is recognized to be the chief cause of death in the world [1].

The role of atherosclerosis as a principal cause of myocardial infarction and thrombosis has been appreciated for many years. However, in spite of what is known about this disease, some of its fundamental characteristics remain poorly recognized and understood [2]. A major problem is that the disease progresses insidiously for many years before symptoms develop making it difficult to follow the early development of the disease in individual patients, and to relate causally the several types of lesions that have been described [3]. For the same reason, identification of the risk factors is to the clinical symptoms rather than on the extent and severity of primary arterial lesion. Not surprisingly many researches in area of atherosclerosis had individual thesis risk factors [4] [5] [6] especially hyperlipidaemia [7] [8] [9] and hypertension [10].

In the last decade, many studies were done to assess the predictive factors for atherosclerosis. One of these factors is microalbuminuria which is defined as excretion of small quantities of albumin in the urine " $30-300 \mathrm{mg} / 24 \mathrm{hr}$ " that is insufficient to be measured by reagent strip [11].

Microalbuminuria was first recognized as the first manifestation of injury to the glomerular filtration barriers and predicts development of overt diabetes nephropathy [12]. Later on, it was found that microalbuminuria predicts atherosclerotic vascular disease in people with insulin dependant diabetes (IDDM), independently of conventional atherogenesis risk factor, diabetic nephropathy, and the duration and control of diabetes [13].

Furthermore, it was also recognized that significant increase in urinary albumin excretion precede the increase in systemic blood pressure during the development of diabetic nephropathy [14].

It was also noticed that non-insulin dependant diabetic subjects with microalbuminuria have an increased mortality rate, especially from cardiovascular diseases. Increased urinary excretion of protein has been shown to be associated with "ECG" changes in non insulindependant diabetes. This was independent of other cardiovascular risk factors [15].

With the progress of studies it was also found that in non-diabetic patients, especially in the presence of essential hypertension, microalbuminuria also predicts the development of atherosclerotic vascular diseases [16].

So all of the above studies described, a possible relation of loss of albumin, even in small quantities, in the urine to the manifestations of atherosclerotic vascular diseases, whether in diabetic or non diabetic patients.

Of the three major plasma proteins "albumin, globulin and fibrinogen" albumin presented in the highest mass concentration [17]. Albumin also has the lowest molecular weight of the major molecules in the plasma, thus, the albumin is the larger contributor to the intravascular colloid osmotic pressure [18]. Albumin is synthesized in the liver and depends on adequate intake and proper 
absorption of dietary proteins [19].

In addition to its contribution in the colloid osmotic pressure, albumin also acts as a carrier molecule for fatty acids, trace elements and many drugs [20]. Serum albumin might be expected to fall with prolonged reduction of protein intake or possible with diminished intake of specific amino acids [21].

The concentration may also fall with variety of infections but although hypoalbuminemia is remarkably reliable indicators of illness, it has little diagnostic specificity. The major effects of low serum albumin concentration "hypoalbuminemia" which occur frequently in liver and kidney diseases is soft tissue edema due to diminished intravascular osmotic pressure. Oedema usually does not appears until the concentration of albumin drop below $2 \mathrm{~g} / \mathrm{dl}$ [22].

In 1992, Gillum and Makue in USA, reported that the age adjusted relative risk factors for Il-ID decreased with increasing concentration of serum albumin in both white men and women [24].

In 1997, Olusi et al. found a similar association between hypoalbuminemia and IHD. They reported in retrospective study which was done on Kuwaiti Arabs with MI admitted to Mubarak AL Kabeer hospital, they reported that a level of serum albumin of less than $4 \mathrm{~g} / \mathrm{dl}$ showed a siginificantly high risk MI than serum albumin concentration of $4.5 \mathrm{~g} / \mathrm{dl}$ and more, suggested an inverse relaytionship between serum albumin concentration and risk of MI [25].

So this study is the first one in Iraq that is designed to be for the association between stroke and hypoalbuminemia. This association is difficult to be clarified, and is it affected by other risk factors of atherosclerosis and stroke and which mechanism or mechanisms explain such association.

\section{Literature Review}

The possible mechanisms were suggested to explain the association between stroke and hypoalbuminemia, these mechanisms may work together.

1) Low serum albumin is secondary to microalbunimuria.

2) The effect of the diseases on the transcapillary leakage of albumin.

a) The role of microalbuminuria

The pathogenic mechanisms linking elevated urinary albumin excretion to atherosclerosis is obscure. It is hypothesized that increased urinary albumin excretion reflects a generalized vascular dysfunction caused by structural alterations of vascular walls, such as reduced content or sulphation of heparin sulphate within extracellular matrix. Such alterations may potentiate albuminuria and several processes involved in atherosclerosis [13].

Lindbergh et al. [26] described the role of sialic acid in atherosclerosis. Sialic acid incorporated to the carbohydrate chain of glycoproteins and glycolipids in serum and tissues and this incorporation has been reported to affect several hemorrhagic factors [27]. Tarstan et al. [13] reported that the predictive effect of elevated sialic acid on development of vascular disease depends on concomitant elevation of urinary albumin excretion. 
b) The effect of the diseases on transcapillary leakage of albumin

Fleck et al. [28] found that the daily loss of albumin to extracellular space " $5 \%$ per hour in healthy individuals" to increased to more than ten times the rate of synthesis during infection, after injury "including surgery" MI and stroke, in patients with malignant diseases and in critically ill patients. So this explained important cause of hypoalbuminemia seen in acute and chronic diseases.

\section{Subjects and Methods}

This study consisted of two groups; first group include 65 patients with stroke admitted to the medical and neurological wards of Baghdad Teaching Hospital in the Medical City from November 2003 to October 2004. Second group, is the control group, which is consisted of 40 persons.

The diagnosis of stroke based on history of typical acute neurological deficits and the initial imaging study of non contrast CT scanning. Careful history were taken from the patient insisting on the onset of symptoms, risk factor, history of hepatic, renal or thyroid diseases and any history of previous operations or blood transfusion and drug history. Proper general and systemic examination was done especially looking for any evidence of hyperlipidemia, carotid bruit, leg and sacral edema and stigmata of liver diseases.

T.S.P., serum albumin, liver function, renal function and general urine examination "GUE” were tested within 48 - $72 \mathrm{hr}$ from the onset of symptoms. Patients with hepatic, renal or thyroid diseases and those with history of diabetes mellitus, previous history of blood transfusion, those receiving diuretics and those with abnormal findings in GUE were excluded from this study.

The control group selection depends upon the absence of history of stroke or IHD or any risk factors "apart from age and sex", no history of organic heart diseases, liver, renal, respiratory or thyroid disease and they should have normal ECG and chest X-ray film. Those persons who had these criteria were chosen from the outpatient clinic in Baghdad Teaching Hospital, companions of patients.

The normal level of serum albumin is $3.5-5 \mathrm{~g} / \mathrm{dl}$ while the normal level of total serum protein is $5.5-8 \mathrm{~g} / \mathrm{dl}$ [28].

The mean serum albumin and total serum protein for the patients and control were calculated and student " $t$ " test was applied to see the statistical significance of hypoalbuminemia and hypoproteinemia instead. Chi square " $X$ ” test also used for comparison between the levels of serum albumin in different groups according to the age, sex, cigarette smoking, hypertension and the presence or absence of carotid bruit. In such comparison we use serum albumin of $3.4 \mathrm{~g} / \mathrm{dl}$ as a cut off point.

Fisher's test also used to compare between two groups when $X^{2}$ test is not applicable.

\section{The Results}

Patients group consisted of 65 patients with acute stroke and control group con- 
sisted of 40 persons. The characteristics of each group are shown in Table 1.

The patients group had mean T.S.P. level of $6.42+0.332 \mathrm{~g} / \mathrm{dl}$ while the mean T.S.P. in control groups is $7.8 \pm 0.257 \mathrm{~g} / \mathrm{dl}$. So the T.S.P. in stroke patients is significantly lower than that of control group $[\mathrm{P}<0.001]$, degree of freedom (df) equal to 103.

The mean serum albumin in patients with stroke is $3.2 \pm 0.251 \mathrm{~g} / \mathrm{dl}$, while the mean serum albumin in control group $[\mathrm{P}<0.001], \mathrm{df}=103$.

Table 2 shows a comparison between both serum albumin and T.S.P. in males and females, this is in patients group. The mean serum albumin in males is 3.27 $\pm 0.25 \mathrm{~g} / \mathrm{dl}$ and in females is $3.23 \pm 0.25 \mathrm{~g} / \mathrm{dl}$, so there is no statistical difference between the two $[P>0.4]$. However, the mean T.S.P. in males is $6.45 \pm 0.33 \mathrm{~g} / \mathrm{dl}$ and in females is $6.39 \pm 0.33 \mathrm{~g} / \mathrm{dl}$. So there is also no significant difference in T.S.P. between males and females $[\mathrm{P}>0.4]$.

Table 3 shows a comparison between serum albumin in those with the serum albumin stroke whose age is below 55 years and those whose age is 55 years and over. This table shows that there is a strong association between increasing age and decreasing serum albumin $\left[X^{2}=25.14, \mathrm{P}<0.005\right]$.

Table 4 shows a comparison between serum albumin in those with stroke and they are hypertensive and those who had stroke but they are not hypertensive. There is a significant association between hypertension and serum albumin $\left[X^{2}\right.$ $=13.34, \mathrm{P}<0.0005]$.

Table 1. The characteristics of patients and control groups.

\begin{tabular}{ccccccc}
\hline Subjects & Total & $\begin{array}{c}\text { Mean } \\
\text { age/years } \\
(\text { range) }\end{array}$ & $\begin{array}{c}\text { No. of } \\
\text { males }\end{array}$ & $\begin{array}{c}\text { No. of } \\
\text { females }\end{array}$ & $\begin{array}{c}\text { Mean } \\
\text { serum } \\
\text { albumin\$ }\end{array}$ & Mean T.S.P.\$ \\
\hline Patients group & 65 & $\begin{array}{c}56.49 \pm 7.06 \\
(40-69)\end{array}$ & 43 & 22 & $3.26 \pm 0.251$ & $6.42 \pm 0.332$ \\
Control group & 40 & $\begin{array}{c}57.9 \pm 6.66 \\
(40-69)\end{array}$ & 19 & 21 & $4.37 \pm 0.206$ & $7.8 \pm 0.257$ \\
\hline
\end{tabular}

*+: standard deviation. $\$:$ measured in gram per $100 \mathrm{ml}$.

Table 2. The serum albumin and T.S.P. in males and females patients group.

\begin{tabular}{cccc}
\hline & Males (range) & Females (range) & P value \\
\hline Mean serum albumin ${ }^{\star}$ & $3.27 \pm 0.25(2.4-3.6)$ & $3.23 \pm 0.33(2.6-3.7)$ & $>0.4$ \\
Mean T.S.P. $₫$ & $6.45 \pm 0.25(5.4-7.4)$ & $6.39 \pm 0.33(5.4-6.9)$ & \\
\hline
\end{tabular}

* \pm : standard deviation. \$: measured in grams per $100 \mathrm{ml}$.

Table 3. The association between serum albumin and the age in patients groups.

\begin{tabular}{ccccc}
\hline Age (years) & $\begin{array}{c}\text { No. of patients with } \\
\text { serum albumin } \\
<3.4 \text { g/dl }\end{array}$ & $\begin{array}{c}\text { No. of patients with } \\
\text { serum albumin } \\
\geq 3.4 \text { g/dl }\end{array}$ & Total No. & P value \\
\hline$<55$ & 8 & 20 & 28 & \\
$\geq 55$ & 33 & 4 & 37 & \\
Total No. & 41 & 24 & 65 & $<0.005$ \\
\hline
\end{tabular}


Table 4. The association between serum albumin and hypertension in patients groups.

\begin{tabular}{cccccc}
\hline $\begin{array}{c}\text { State of blood } \\
\text { pressure }\end{array}$ & $\begin{array}{c}\text { No. of patients with serum } \\
\text { albumin }< \\
\mathbf{3 . 4} \mathbf{~ g / d l}\end{array}$ & $\begin{array}{c}\text { No. of patients with } \\
\text { serum albumin } \\
>\mathbf{3 . 4} \text { g/dl }\end{array}$ & Total & P value \\
\hline Hypertensive & 22 & 2 & 24 & \\
Non-hypertensive & 19 & 22 & 41 & \\
Total No. & 41 & 24 & 65 & $<0.0005$ \\
\hline
\end{tabular}

Table 4 shows a comparison between serum albumin in those withstroke and they are hypertensive and those who had stroke but they are not hypertensive. There is a significant association between hypertension and serum albumin $\left[X^{2}\right.$ $=13.34, \mathrm{P}<0.0005$ ].

Table 5 shows the relation between serum albumin and presence ofcarotid bruit in diseases group. There is a significant association between low serum albumin and the presence of carotid bruit [ $\mathrm{P}<0.005$ "Fisher's test"].

Among 65 patients with stroke, 12 patients $18.46 \%$ had carotid bruit. Of these 65 patients, 8 patients had past history of IHD, 5 patients out of 8 had carotid bruit and the other 3 had not. Two patients of 65 had past history of cerebrovascular diseases, one of them had carotid bruit and the other had not. 24 patients had hypertension out of 65 patients with stroke, 8 of them had carotid bruit and 16 had not. Of 65 patients with stroke, 47 patients were smokers, nine of them had carotid bruit and 38 patients hadn't. Table 6 simplifies these findings.

Table 7 shows the significance of serum albumin with cigarette smoking in patients group. This association is statistically significant $\left[X^{2}=15.57, \mathrm{P}<0.025\right]$.

To see the association between serum albumin in non smokers and exsmokers, we applied $X^{2}$ test. These is no significant difference between non smokers and ex-smokers $\left[X^{2}=0.3794, \mathrm{P}>0.05\right]$.

To compare between serum albumin according to the amount of cigarette smoking also $X^{2}$ test was used and we found that is no significant difference in serum albumin no matter how many cigarette per day the patients smoke $\left[X^{2}=\mathrm{I}\right.$ $0.69, \mathrm{P}>0.25]$.

\section{Discussion}

We had reported an important finding in this study which deserves comment, that is the strong statistical association between stroke and both hypoalbuminemia and hypoproteinemia.

Although methodology of our study differs from the previous studies in the world regarding this subject, this report is consistent with previous observations of the relation between IHD and low serum albumin [22] [23] [24] [25].

The strength of association was of the same magnitude as that between increasing age and low serum albumin. However, there is no such relation between the serum albumin and gender. The decrement of serum albumin with increasing age had also been reported in different previous studies [23]-[32]. 
Table 5. The association between carotid bruit and serum albumin in patients group.

\begin{tabular}{ccccc}
\hline Carotid bruit & $\begin{array}{c}\text { No. of patients with } \\
\text { serum albumin }<3.4 \text { g/dl }\end{array}$ & $\begin{array}{c}\text { No. of patients with } \\
\text { serum albumin }>3.4 \text { g/dl }\end{array}$ & Total & P value \\
\hline Present & 12 & & 12 & \\
Absent & 29 & 24 & 53 & \\
Total No. & 41 & 24 & 65 & $<0.005$ \\
\hline
\end{tabular}

Table 6. The frequency of risk factors in patients with and without carotid bruit

\begin{tabular}{cccc}
\hline & $\begin{array}{c}\text { Total } \\
\text { No. }\end{array}$ & Bruit & No bruit \\
\hline Acute stroke & 65 & $12(18.46 \%)$ & $53(81.54 \%)$ \\
Patients with stroke and past history of IHD & 8 & $5(26.5 \%)$ & $3(37.5 \%)$ \\
$\begin{array}{c}\text { Patients with stroke and past history of CVA } \\
\text { Patients with stroke and hypertension }\end{array}$ & 2 & $1(50 \%)$ & $1(50 \%)$ \\
Patients with stroke and they are smoking & 47 & $9(19.15 \%)$ & $38(80.85 \%)$ \\
\hline
\end{tabular}

Table 7. The association between serum albumin and cigarette smoking.

\begin{tabular}{cccc}
\hline Cigarettes per day & $\begin{array}{c}\text { No. of patients with serum } \\
\text { albumin }<3.4 \text { g/dl }\end{array}$ & $\begin{array}{c}\text { No. of patients with serum } \\
\text { albumin }>3.4 \text { g/dl }\end{array}$ & Total No. \\
\hline Non smoker & 8 & 10 & 18 \\
Ex-smoker & 6 & 10 & 16 \\
$<10$ & 2 & 1 & 3 \\
$10-20$ & 11 & 2 & 13 \\
$>20$ & 14 & 1 & 15 \\
Total No. & 41 & 24 & 65 \\
\hline
\end{tabular}

This decrement is probably related to the normal physiological aging process which occurs, possibly, as a result of decrease hepatic functions with aging or might be due to past translational changes in protein synthesis, such as deamination, oxidation, cross linking and non enzymatic glycation, that increased with aging process [33]. Atherosclerosis is known as progressive disease of aging and accordingly plays an important role in development of stroke [34]. So both stroke and increasing age are associated with low serum albumin this means that hypoalbuminemia runs parallel with process of atherosclerosis furthermore; the low serum albumin that occur with increasing age is therefore potentiated by other risk factors for atherosclerosis that's associated with hypoalbuminemia and increase with increasing age, like hypertension, cigarette smoking and sedentary life.

The lack of association between hypoalbuminemia and sex is probably related to the fact that the incidence of stroke is equal in both sexes after [35], and since all our female patients, in this study, are in their menopausemenopause state, so no difference in serum albumin seen between men and women. 
Hypertension is a major modifiable risk factor for stroke [36]. In our study, there is strong association between hypertension and hypoalbuminemia. There is no previous study, link such association, to be compared with. However, it is well known that microalbuminuria is associated, and even precedes the development of hypertension in diabetic patient [14], and microalbuminuria is associated with nocturnal systolic hypertension in diabetics [37], and the role of microalbuminuria in atherosclerotic vascular changes had been previously explained in the introduction. So the association between hypertension and low serum albumin probably related to the occurrence of microalbuminuria which is needed to be studied further. However, since hypertension is associated with aging process and since aging is associated with low serum albumin, as mentioned above, this may also potentiate hypoalbuminemia in hypertensives. Furthermore, hypertension is also associated with other risk factor like abnormalities of lipoproteins and hyperinsulinemia [33].

Carotid bruit indicates an advanced atherosclerotic vascular change and since there is strong statistical association between carotid bruit and hypoalbuminemia, this may explain a probable role of hypoalbuminemia in atherosclerosis. No previous reports studied such correlation. The clinical significance of carotid bruit in stroke had been previously fully studied [38].

In this study, we found that about $18 \%$ of patients with stroke had carotid bruit. In Saudi Arabia, 50\% of patients with cerebrovascular diseases who had carotid bruit, had IHD.

The possibility of having carotid bruit is greater when there is previous history of IHD, CVA, hypertension and smoking and all of these indicate atherosclerotic vascular diseases.

In this study, cigarette smoking is significantly associated with low serum albumin. These findings are consistent with Philip et al. study [23]. Also our study demonstrate that there is no significant difference in serum albumin between those who never smoke and ex-smoker and there is no statistical difference in the serum albumin among smokers whatever the amount smoked. These findings are also consistent with Philip et al. study. This may reflect the reversible effect of cigarette smoking on vasculopathy.

Smoking can lead to atherosclerosis, IHD and stroke by different mechanisms like alterations of lipoproteins, endothelial platelet activation and clotting, vasoconstriction due to endothelial dysfunction, increased blood pressure and release of free radicals [39].

\section{Conclusion and Recommendation}

Hypoalbuminemia is significantly associated with stroke, and such association is needed to be further investigated in regard with urinary excretion of albumin and correlation with the level of serum lipids.

There is no difference in the serum albumin among smokers regardless of the amount smoked. Similarly there is no significant differences in the serum albu- 
min between those who never smoke and ex-smokers. This reflects the reversible effect of smoking on vasculopathy.

\section{Conflicts of Interest}

The authors declare no conflicts of interest regarding the publication of this paper.

\section{References}

[1] Wyngaarden, J.B. and Smith, L.H. (1985) Cecil Textbook of Medicine. 17th Edition, Saunders Company, Philadelphia.

[2] Rose, R. and Glomest, J.A. (1976) Pathogenesis of Atherosclerosis. The New England Journal of Medicine, 295, 369-377. https://doi.org/10.1056/NEJM197608122950707

[3] Ross, R. (1993) The Pathogenesis of Atherosclerosis: A Prospective for the 1990s. Nature, 362, 801-809. https://doi.org/10.1038/362801a0

[4] Harker, L.A., Slichtor, S., Scott, C.R., et al. (1974) Homocysteinemia, Vascular Injury and Arterial Thrombosis. The New England Journal of Medicine, 291, 537-543. https://doi.org/10.1056/NEJM197409122911101

[5] Shaper, A.G., Wannamethee, S.G. and Walker, M. (1997) Body Weight: Implications for the Prevention of Coronary Heart Diseases, Stroke, and Diabetes Mellitus in Cohort Study of Middle Aged Men. BMJ, 314, 1311-1317. https://doi.org/10.1136/bmj.314.7090.1311

[6] Ockene, I.S. and Miller, NH. (1997) Cigarette Smoking, Cardiovascular Disease, and Stroke: A Statement for Healthcare Professionals from the American Heart Association. American Heart Association Task Force on Risk Reduction. Correlation, 96, 3243-3247.

[7] Kannel, W.B., Castelli, W., Gordon, T., et al. (1991) Serum Cholesterol, Lipid Protein and Coronary Heart Diseases: The Framingham Study. Annals of Internal Medicine, 74, 1-12. https://doi.org/10.7326/0003-4819-74-1-1

[8] Miller, N.E. (1987) Association of High Density Lipoprotein Subclasses and Apolipoproteins with IHD and Atherosclerosis. American Heart Journal, 113, 589-597. https://doi.org/10.1016/0002-8703(87)90638-7

[9] Meller, G.J. and Miller, N.E. (1975) Plasma-HDL Concentration and the Development of 1HD. The Lancet, 1, 9-19.

[10] Mc Mahan, S., Pete, R., Cutter, J., et al. (1990) Blood Pressure, Stroke and Coronary Heart Diseases. Part I. Prolonged Differences in Blood Pressure: Prospective Observational Studies Corrected for the Progressive Dilution Bias. The Lancet, 335 , 765-774. https://doi.org/10.1016/0140-6736(90)90878-9

[11] Molitch, M.E. (1997) Management of Early Diabetic Nephropathy. The American Journal of Medicine, 102, 392-398. https://doi.org/10.1016/S0002-9343(97)00118-6

[12] Cooper, M.E. (1998) Pathogenesis, Prevention, and Treatment of Diabetic Nephropathy. The Lancet, 352, 213-218. https://doi.org/10.1016/S0140-6736(98)01346-4

[13] Dockort, T., Yokoyama, H., Skovjenset, J., et al. (1996) Control Study of Predictive Value of Urinary Albumin Excretion for Atherosclerotic Vascular Diseases Patients with Insulin Dependant Diabetes Mellitus. BMJ, 312, 871-874. https://doi.org/10.1136/bmj.312.7035.871

[14] Mathisen, E.R., Ronn, B., Jensen, J., Storm, B. and Deckert, J. (1990) Relationship 
between Blood Pressure and Urinary Albumin Excretion in Development of Microalbuminuria. Diabetes, 39, 245-249. https://doi.org/10.2337/diab.39.2.245

[15] Mattock, M.B., Morrish, N.J., Viberti, G.C., Keen, H., Fitzgerald, A.P. and Jackson, G. (1992) Prospective Study of Microalbuminuria as Predictor of Mortality in NIDDM. Diabetes, 41, 736-741. https://doi.org/10.2337/diab.41.6.736

[16] Yudkin, J.S., Forrest, R.D. and Jackson, C.A. (1988) Microalbuminuria as a Predictor of Vascular Disease in Non Diabetic Subjects. The Lancet, 2, 530-533. https://doi.org/10.1016/S0140-6736(88)92657-8

[17] Martin, D.W. (1981) The Plasma Proteins. In: Mayer, P.A., David, W. and Rodwell, V.W., Eds., Harper's Review of Biochemistry, 18th Edition, Lang Medical Publications, 54-56.

[18] Austein, F., Allumin, H. and Ian, D.K. (1988) Biochemistry. 2nd Edition, Wiley Media, New York.

[19] Abrahams, W. (1978) Plasma Protein. In: Abraham, W., Ed., Principles of Biochemistry, 6th Edition, McGrew-Hill, New York, 145-147.

[20] Guyten, A.C. (1986) Circulation. In: Guyton, A.C., Ed., Textbook of Medical Physiology, 7th Edition, WB Saunders, Philadelphia, 89-111.

[21] Walter, J.B. and Israel, M.S. (1987) The Plasma Proteins. In: Walter, J.B., Ed., General Pathology, 6th Edition, Churchill Livingstone, London, 32-39.

[22] Daniel, K. (1998) Derangements of Hepatic Metabolism. In: Fauci, A.S., Bramwald, E., et al., Eds., Harrison's Principles of Internal Medicine, MCGrew Hill, New York, 222-239.

[23] Philips, A., Shaper, A.G. and Whincup, P.H. (1989) Association between Serum Albumin and Mortality from Cardiovascular Disease, Cancer \& Other Cause. The Lancet, 2, 1434-1436. https://doi.org/10.1016/S0140-6736(89)92042-4

[24] Gillum, R.F. and Makue, D.I.M. (1992) Serum Albumin, Coronary Heart Disease and Death. American Heart Journal, 123, 507-513.

https://doi.org/10.1016/0002-8703(92)90667-K

[25] Oas, S.O., Prabla, K. and Sugathan, T.N. (1997) Significant Hypoalbuminemia, Hypoproteinemia Associated with Myocardial Infarction in a Kuwait Arabs Population. Annals of Saudi Medicine, 17, 124-125. https://doi.org/10.5144/0256-4947.1997.124

[26] Lindberg, G., Eklund, G.A., Gulberg, B. and Rastaml, L. (1991) Serum Sialic Acid Concentration and Cardiovascular Mortality. BMJ, 302, 143. https://doi.org/10.1136/bmj.302.6769.143

[27] Orekhor, A.N., Torter, V.V. and Mukhim, D.N. (1991) Desialylated Low Density Lipoprotein-Naturally Occurring Modified Lipoprotein with Atherogenic Potency. Atherosclerosis, 86, 153-161. https://doi.org/10.1016/0021-9150(91)90211-K

[28] Fleck, A., Rainer, G., Hawker, F., et al. (1985) Increased Vascular Permeability and Major Cause of Hypoalbuminemia in Disease and Injury. The Lancet, 1, 781-783. https://doi.org/10.1016/S0140-6736(85)91447-3

[29] Schitzer, J.E. and Punney, E. (1992) Quantitation of Specific Finding of Orosemanacid to Cultured Microvascular Endothelium, Role in Capillary Permeability. 32, H48-H55.

[30] Erenil, G., Erebas, D. and Aysel, A. (1993) Free Radials and Antioxidant Systems. Materia Medica Palana, 1, 37-43.

[31] Anthony, S., Fauci, E.B., et al. (1998) Laboratory Data of Clinical Significant. In: Kasper, D., et al., Eds., Harrison's Principles of Internal Medicine, 18th Edition, 
McGrew Hill, New York, 463-471.

[32] Corti, M.-C., et al. (1994) Serum Albumin and Physical Disability as Predictors of Mortality in Older Persons. JAMA, 272, 1036. https://doi.org/10.1001/jama.1994.03520130074036

[33] Robert, L.K. (1994) Changes Associated with Normal Aging. In: Robert, L.K., Joseph, G.O. and Itamar, B.A., Eds., Essential of Clinical Geriatrics, 3rd Edition, McGrew Hill Inc., New York, 53-61.

[34] Heil, M.R. (1998) Geriatric Medicine. In: Anthony, S.F., Brunwald, E., et al., Eds., Harrison's Principles of Internal Medicine, 14th Edition, McGrew Hill, New York, 95-117.

[35] William, W.P. (1997) Nonlipolipoprotein Risk Factors of Coronary Heart Disease: Evaluation and Management. American Journal of Medicine, 102, 7-13.

[36] Alan, R. and James, S.F. (1997) The Secondary Prevention of Coronary Artery Disease. American Journal of Medicine, 102, 572-580. https://doi.org/10.1016/S0002-9343(97)00046-6

[37] Teresa, H., Beatrice, N., Mike, H., Cornelins, C., Habib, B. and Geraldine, G. (1997) Microalbuminuria in Patients with Non Insulindependant Diabetes Mellitus Relates to Nocyurnal Systolic Blood Pressure. American Journal of Medicine, 102, 531. https://doi.org/10.1016/S0002-9343(97)00051-X

[38] Adnan, A., Peter, A., Saod, A.R. and Thir, O. (1996) Carotid Bruit and Ischemic Cerebrovascular Disease. Annals of Saudi Medicine, 16, 218-220.

[39] Halbrook, J.H., Grundy, S.M., Heineker, C.H., Kannell, W.B. and Streng, J.P. (1992) Cigarette Smoking and Cerebrovasular Disease, Statement for Heart Professionals. Circulation, 86, 1664-1669. https://doi.org/10.1161/01.CIR.86.5.1664 